Three-Dimensional Imaging, Change Detection, and Stability Assessment during the Centerline Trench Levee Seepage Experiment Using Terrestrial Light Detection and Ranging Technology, Twitchell Island, California, 2012

By Gerald W. Bawden, James Howle, Sandra Bond, Michelle Shriro, and Peter Buck

Open-File Report 2014-1092

U.S. Department of the Interior

U.S. Geological Survey 


\section{U.S. Department of the Interior \\ SALLY JEWELL, Secretary}

\section{U.S. Geological Survey \\ Suzette M. Kimball, Acting Director}

U.S. Geological Survey, Reston, Virginia: 2014

For more information on the USGS-the Federal source for science about the Earth,

its natural and living resources, natural hazards, and the environment-visit

http://www.usgs.gov or call 1-888-ASK-USGS

For an overview of USGS information products, including maps, imagery, and publications, visit $h$ ttp://www.usgs.gov/pubprod

To order this and other USGS information products, visit http://store.usgs.gov

Suggested citation:

Bawden, G.W., Howle, James, Bond, Sandra, Shriro, Michelle, and Buck, Peter, 2014, Three-dimensional imaging, change detection, and stability assessment during the centerline trench levee seepage experiment using terrestrial light detection and ranging technology, Twitchell Island, California, 2012: U.S. Geological Survey Open-File Report 2014-1092, 28 p., http://dx.doi.org/10.3133/ofr20141092.

ISSN 2331-1258 (online)

Any use of trade, firm, or product names is for descriptive purposes only and does not imply endorsement by the U.S. Government.

Although this information product, for the most part, is in the public domain, it also may contain copyrighted materials as noted in the text. Permission to reproduce copyrighted items must be secured from the copyright owner. 


\section{Contents}

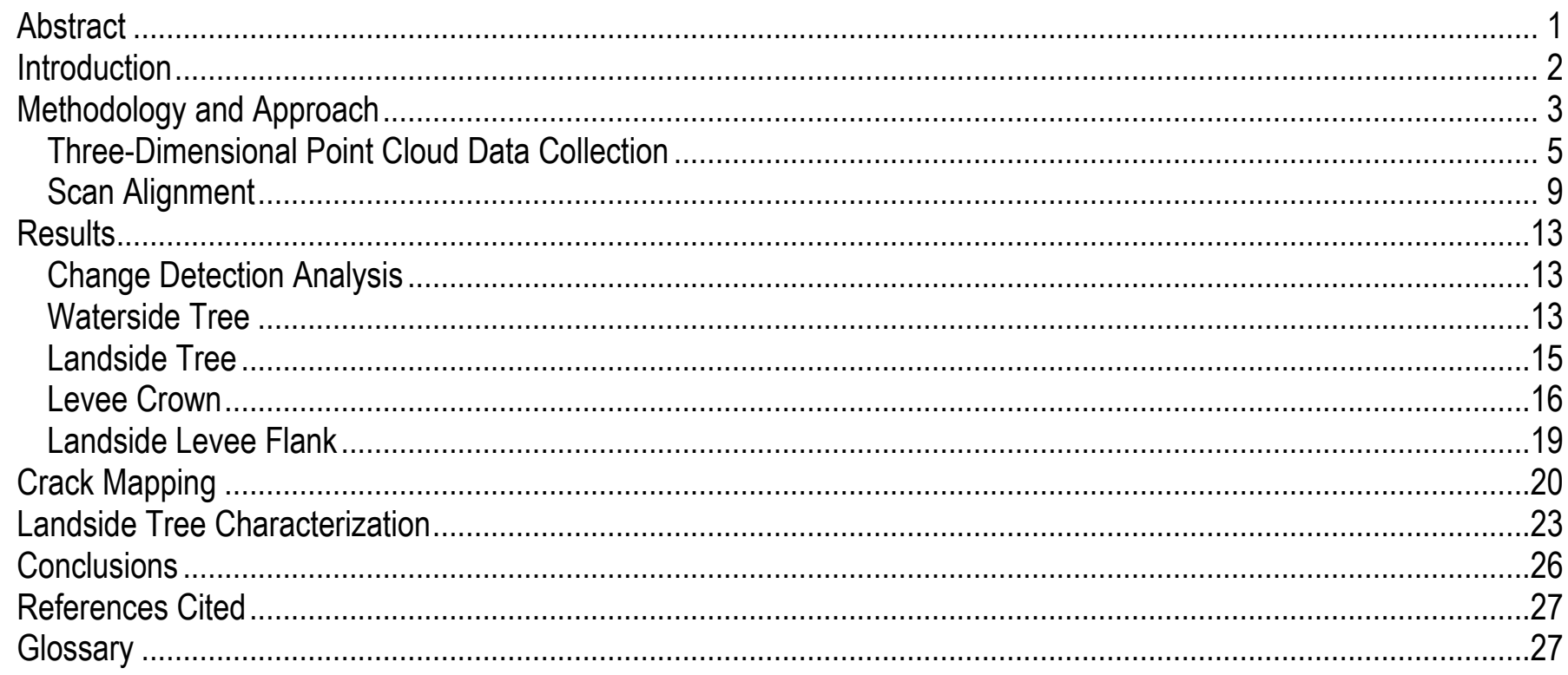

\section{Figures}

Figure 1. Map of Twitchell Island seepage test site, California ……………...................................................... 3

Figure 2. Schematic diagram showing phase shift and phase modulation........................................................ 7

Figure 3. Example of terrestrial light detection and ranging point cloud map of the imaged levee (epoch 3) with scanner setup locations, reference frame sphere locations, and temporary alignment sphere locations

Figure 4. Three-dimensional anaglyph visualization of the point cloud data of $(A)$ the levee crown, alignment spheres, and seepage trench image; and $(B)$ the tilted waterside tree with white points showing the initial position of the tree and the colorized point cloud showing the data collected at the end of the project

Figure 5. Point-cloud imagery shows 20.67 degrees of rotation of the waterside tree from the pre-seepage test scan on April 4, 2012, (white) and the final survey on June 6, 2012, (blue) with the best-fit cylinder for the J une dataset.

Figure 6. Difference map showing displacement pattern on the landside tree between $(A)$ April 4-June 6, 2012, and (B) May 29-June 6, 2012, Twitchell Island, California

Figure 7. Photograph of $(A)$ the laser scanner imaging a prominent crack in a connecting wall at the northern end of the primary seepage trench and elevational difference maps across the crack from

(B) April 9-May 29, 2012, and (C) April 9-June 6, 2012, Twitchell Island, California

Figure 8. Colorized vertical change map focusing on the levee crown, Twitchell Island, California, between April 9 and June 6, 2012

Figure 9. Difference map showing \pm 5.0 centimeters $(\mathrm{cm})$ of vertical change on the levee flank and crown, Twitchell Island, California, between May 29 and June 6, 2012.

Figure 10. Photographs showing cracks on the levee crown, Twitchell Island, California, 2012 …......................... 21

Figure 11. Terrestrial light detection and ranging (T-Lidar) analysis of cracks on the levee crown,

Twitchell Island, California, 2012

Figure 12. Characterization of the landside tree, Twitchell Island, California, 2012.

Figure 13. Levee parallel, perpendicular, and map view cross-sectional areas (solid yellow) derived from the terrestrial light detection and ranging point cloud canopy mesh (transparent yellow with blue wireframe of the mesh) of the landside tree, proximal to the seepage trench, Twitchell Island, California, 2012 


\section{Tables}

Table 1. Data collection and alignment statistics, Twitchell Island, California, 2012

Table 2. TerraScan ${ }^{\mathrm{TM}}$ parameters used to classify (a-upper) ground points and (b-lower) vegetation points,

Twitchell Island, California, 2012

\section{Conversion Factors}

Inch/Pound to SI

\begin{tabular}{|c|c|c|}
\hline Multiply & By & To obtain \\
\hline \multicolumn{3}{|c|}{ Length } \\
\hline foot (ft) & 0.3048 & meter (m) \\
\hline
\end{tabular}

SI to Inch/Pound

\begin{tabular}{lll}
\hline \multicolumn{1}{c}{ Multiply } & By & To obtain \\
\hline centimeter $(\mathrm{cm})$ & Length & \\
millimeter $(\mathrm{mm})$ & 0.3937 & inch (in.) \\
meter $(\mathrm{m})$ & 0.03937 & inch (in.) \\
meter $(\mathrm{m})$ & 3.281 & foot (ft) \\
\hline & 1.094 & yard (yd) \\
\hline square meter $\left(\mathrm{m}^{2}\right)$ & Area & \\
\hline square centimeter $\left(\mathrm{cm}^{2}\right)$ & 0.0002471 & acre \\
\hline square meter $\left(\mathrm{m}^{2}\right)$ & 0.001076 & square foot $\left(\mathrm{ft}^{2}\right)$ \\
\hline square centimeter $\left(\mathrm{cm}^{2}\right)$ & 10.76 & square foot $\left(\mathrm{ft}^{2}\right)$ \\
\hline
\end{tabular}

Vertical coordinate system is unreferenced in this project. The vertical reference frame is local and in meters from the southeastern corner of the dataset. Horizontal was measured by an internal level within the T-Lidar system. Horizontal coordinate system is unreferenced. The horizontal coordinate system is fixed to the southeastern corner of the dataset with the $\mathrm{X}$ axis parallel to the levee and the $\mathrm{Y}$ axes perpendicular. All units are in meters. 


\title{
Three-Dimensional Imaging, Change Detection, and Stability Assessment during the Centerline Trench Levee Seepage Experiment Using Terrestrial Light Detection and Ranging Technology, Twitchell Island, California, 2012
}

\author{
By Gerald W. Bawden, James Howle, Sandra Bond, Michelle Shriro, and Peter Buck
}

\begin{abstract}
A full scale field seepage test was conducted on a north-south trending levee segment of a now bypassed old meander belt on Twitchell Island, California, to understand the effects of live and decaying root systems on levee seepage and slope stability. The field test in May 2012 was centered on a north-south trench with two segments: a shorter control segment and a longer seepage test segment. The complete length of the trench area measured 40.4 meters $(\mathrm{m})$ near the levee centerline with mature trees located on the waterside and landside of the levee flanks. The levee was instrumented with piezometers and tensiometers to measure positive and negative porewater pressures across the levee after the trench was flooded with water and held at a constant hydraulic head during the seepage test - the results from this component of the experiment are not discussed in this report. We collected more than one billion three-dimensional light detection and ranging (lidar) data points before, during, and after the centerline seepage test to assess centimeter-scale stability of the two trees and the levee crown. During the seepage test, the waterside tree toppled (rotated 20.7 degrees) into the water. The landside tree rotated away from the levee by 5 centimeters $(\mathrm{cm})$ at a height of $2 \mathrm{~m}$ on the tree. The paved surface of the levee crown had three regions that showed subsidence on the waterside of the trench-discussed as the northern, central, and southern features. The northern feature is an elongate region that subsided $2.1 \mathrm{~cm}$ over an area with an average width of $1.35 \mathrm{~m}$ that extends $15.8 \mathrm{~m}$ parallel to the trench from the northern end of the trench to just north of the trench midpoint, and is associated with a crack $1 \mathrm{~cm}$ in height that formed during the seepage test on the trench wall. The central subsidence feature is a semicircular region on the waterside of the trench that subsided by as much as $6.2 \mathrm{~cm}$ over an area $3.4 \mathrm{~m}$ wide and $11.2 \mathrm{~m}$ long. The southern feature is an elongate region that has a maximum subsidence of $3.5 \mathrm{~cm}$ over an area $0.75 \mathrm{~m}$ wide and $8.1 \mathrm{~m}$ long and is associated with a number of small fractures in the pavement that are predominately north-south-trending and parallel to the trench. We determined that there was no significant motion of the levee flank during the last week of the seepage test. We also determined biomorphic parameters for the landside tree, such as the $3 \mathrm{D}$ positioning on the levee, tree height, levee parallel/perpendicular cross sectional area, and canopy centroid. These biomorphic parameters were requested to support a University of California Berkeley team studying seepage and stability on the levee. A gridded, 2-cm bare-earth digital elevation model of the levee crown and the landside levee flank from the final terrestrial lidar (T-Lidar) survey provided detailed topographic data for future assessment. Because the T-Lidar was not integrated into the project design, other than an initial courtesy dataset to help characterize the levee surface, our ability to contribute to the overall science goals of the seepage test was limited. Therefore, our analysis focused on developing data collection and processing methodology necessary to align ultra highresolution T-Lidar data (with an average spot spacing 2-3 millimeters on the levee crown) from several instrument setup locations to detect, measure, and characterize dynamic centimeter-scale deformation and surface changes during the seepage test.
\end{abstract}




\section{Introduction}

In advance of the implementation of a planned U.S. Army Corps of Engineers planned policy that prohibits trees within $15 \mathrm{ft}(4.57 \mathrm{~m})$ of levees and floodwalls, the California Department of Water Resources (DWR), Sacramento Area Flood Control Agency, the U.S. Army Corps of Engineers, University of California Berkeley (UCB), the University of California Davis, and the U.S, Geological Survey are studying the effect that trees have on levees. This study is one of several commissioned studies by the California Levee Vegetation Research Program (CLVRP) to help understand if trees help to stabilize levees or act as possible points of failure. The CLVRP is a joint effort of DWR, SAFCA, Central Valley Flood Protection Board, U.S. Fish and Wildlife Service, National Oceanic and Atmospheric Administration Fisheries Service, California Department of Fish and Wildlife, and the California Central Valley Flood Control Association.

The overall objective of the CLVRP-funded Centerline Trench Levee Seepage and Stability Study at Twitchell Island was to characterize how an active levee responds to water seepage near trees growing on the landside and waterside of the levee (fig. 1). This site was selected because it is an active levee segment with an established soil moisture saturation gradient through the levee that would naturally respond to the increased water flow of the test. It also has lone trees on the waterside and landside of the levee. Furthermore, the site was selected because the levee section had been bypassed with a newer levee to the south and east; so if the levee was compromised during the test, only a small field to the east would be flooded (fig. 1, inset). This trench study was led by a team from the UCB who excavated a two-segment trench: the shorter northern portion was the control segment and the longer southern portion was the test segment. The trench was created along the levee centerline and was cut through the paved levee crown. Once the trench was created, it was filled with gravel and a known volume of water was pumped into the trench. The bi-directional flow was then measured with an array of instruments systematically installed on the waterside and landside of the levee. The results from the seepage test will not be discussed here as they are part of a UCB doctoral dissertation by Michelle Shriro, who is also a co-author on this report.

The goal of the terrestrial light detection and ranging (T-Lidar) survey was to record threedimensional (3D) changes to the levee surface and nearby trees as the seepage test progressed. It must be noted that T-Lidar was not a preplanned element of the study. The USGS Western Remote Sensing and Visualization Center was involved in other CLVRP studies and was asked to collect an initial set of T-Lidar scans on April 9, 2012, hours before the trench was excavated to help provide context and visualization for the study. Two more surveys were added to the project after the study began, and a large tree on the waterside of the levee had toppled over. 


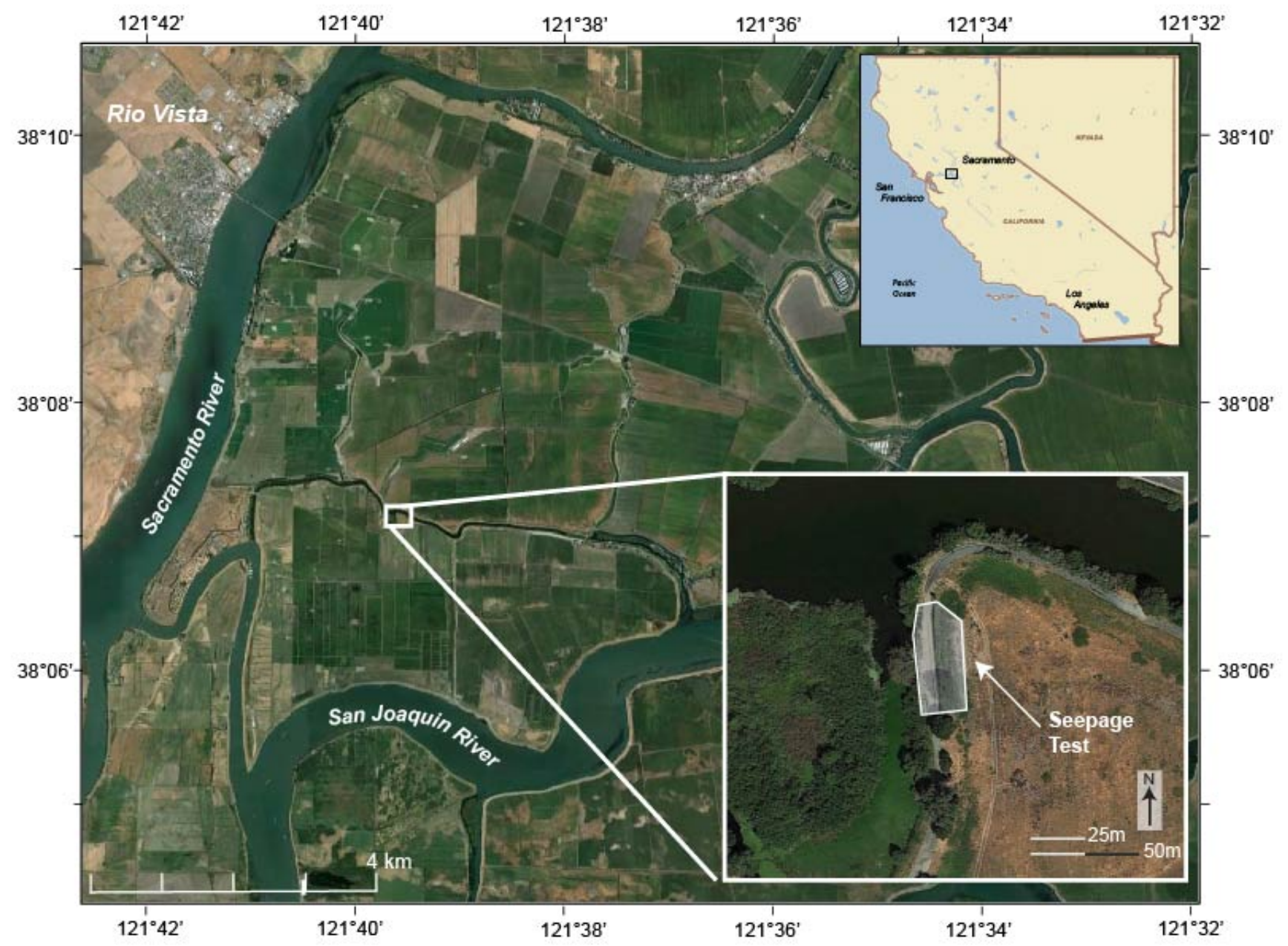

Figure 1. Map of Twitchell Island seepage test site, California. The gray region in the lower inset is the terrestrial light detection and ranging extent.

\section{Methodology and Approach}

Data were collected at the site three times between April and June 2012: (1) an initial survey before the trench was created (April 9, 2012), (2) a mid-experiment survey (May 29, 2012), and (3) a final survey at the project completion (June 6,2012) (table 1). The initial baseline scan was collected at the onset of the study to assist the UCB team with providing a 3D framework for their analysis; the TLidar survey focused on the levee crown and on the two trees, one located on the waterside of the levee and the other located on the land side of the levee. T-Lidar for change detection was not originally planned for this project. Therefore, a rigorous geodetic reference frame was not established during the first survey, which primarily focused on the levee crown and the landside and waterside trees that were visible to provide visual and topographic context for the trench experiment. 
During the testing, the tree on the waterside of the levee toppled and new cracks appeared in the paved levee crown. As a result, two T-Lidar surveys were added to the project to document further changes to the levee surface. The second survey was conducted after the seepage test began and a few days after the waterside tree had toppled. The final survey was conducted at the conclusion of the seepage tests and imaged the full region. There was a substantial amount of grass on the landward flanks of the levee which obscured most of the land surface during the first survey, thereby diminishing the application of T-Lidar technology to measure subtle changes to the ground surface on the levee flanks associated with the seepage test. A change assessment of the levee flanks could only be made for the time between the second and final surveys.

Table 1. Data collection and alignment statistics, Twitchell Island, California, 2012.

[The alignment statistics were calculated from the target sphere center point coordinates. The root mean square (RMS) misfit describes the discrepancy in the overall coordinate system between the position and the orientation of two corresponding reference objects. The RMS misfit within a given survey is an average discrepancy calculated from all corresponding reference objects within a survey. The RMS misfit of the survey to the other epochs is an average discrepancy calculated from all corresponding reference objects between epochs. Abbreviation: mm, millimeter]

\begin{tabular}{ccccccc}
\hline $\begin{array}{c}\text { Survey } \\
\text { dates }\end{array}$ & $\begin{array}{c}\text { Number of } \\
\text { instrument } \\
\text { setups }\end{array}$ & $\begin{array}{c}\text { Number of } \\
\text { scans }\end{array}$ & $\begin{array}{c}\text { Number of data } \\
\text { points }\end{array}$ & $\begin{array}{c}\text { Number of } \\
\text { alignment } \\
\text { spheres used }\end{array}$ & $\begin{array}{c}\text { RMS misfit within } \\
\text { a given survey } \\
\text { (mm) }\end{array}$ & $\begin{array}{c}\text { RMS misfit of the } \\
\text { survey to the other } \\
\text { epochs } \\
\text { (mm) }\end{array}$ \\
\hline April 9 & 4 & 4 & $42,488,886$ & 5 & $1.2 \pm 0.1$ & 1.6 \\
May 29 & 9 & 9 & $725,218,261$ & 11 & $2.7 \pm 0.1$ & 3.1 \\
June 6 & 14 & 15 & $250,766,155$ & 22 & $2.4 \pm 0.1$ & 3.1 \\
Total & 27 & 28 & $1,018,473,302$ & & & $2.9 \pm 0.1$ \\
\hline
\end{tabular}




\section{Three-Dimensional Point Cloud Data Collection}

We used a FARO ${ }^{\circledR}$ Focus $^{3 \mathrm{D}} 120$ to collect sub-centimeter spot spacing 3D data along the crown and landward toe of the levee. The FARO Focus ${ }^{3 \mathrm{D}}$ can collect 976,000 points per second and has a scanning field of view that is 360 degrees (horizontal) by 305 degrees (vertical, with 55 degrees data gap directly beneath the scanner), with a beam divergence of 0.19 milliradians (0.011degrees) and a beam diameter of $3.0 \mathrm{~mm}$ (FARO Technologies, Inc., 2013). The scanner has a dual axis compensator that internally levels the instrument with an accuracy of 0.015 degrees. The accuracy of each individual xyzi (3D position with $i$ as intensity) point cloud data point is $\pm 2.0 \mathrm{~mm}$, for uncorrected raw data. However, the FARO Focus ${ }^{3 \mathrm{D}}$ has a noise compression approach that can collect and average either 2-, 4-, or 8-point measurements for each observed location on the ground/target to improve the overall accuracy of the measured 3D point - the accuracy improves to 0.5 and $1.1 \mathrm{~mm}$ with 4-point averaging based on target reflectiveness (90 and 10 percent, respectively) at a distance of $25 \mathrm{~m}$ from the scanner (FARO Technologies, Inc., 2013). Most of the data collected for this project used the 4-point measurement averaging, ranging-noise compression approach that resulted in less than $1.1 \mathrm{~mm}$ pointposition accuracy for each scan.

The FARO T-Lidar system is a phase-shift based laser scanner that, in ideal conditions, can collect accurate, less than or equal to $1.1 \mathrm{~mm}$ uncertainty $3 \mathrm{D}$ point cloud data to a distance out to 153.49 $\mathrm{m}(120 \mathrm{~m}$ to a 90 percent reflective target; most natural targets are reflective at $20-30 \mathrm{~m}$ during midday sun). The phase-shift approach uses a laser that emits a continuous sinusoidal laser beam that travels from the instrument, reflects off the target, and travels back to the scanner (FARO Technologies, Inc., 2012a). The phase shift is the difference in the peaks between the "emitted laser" beam and the peaks of the "returned laser" beam (fig. $2 A$;) Pfeifer and Briese, 2008). The distance the pulse travel is calculated by the following equation:

$$
\text { Distance }=(\text { Speed_of_light } \times \text { time_of_flight }) / 2
$$

Phase shift can be represented by:

$$
\text { Phase Shift }=2 \pi \times \text { time_of_flight } \times \text { modulation_frequency }
$$

Equation 2 can be solved for time of flight and entered into equation 1 to solve for distance.

$$
\text { Distance }=\text { speed of light } \times(\text { Phase shift } /(2 \pi \times \text { modulation_frequency }) / 2
$$

The phase-shift approach cannot resolve distances that exceed maximum modulation frequency because this approach can only resolve the phase shift for one full sinusoidal wave cycle. Any phase return that exceeds this distance would theoretically be mapped into the first phase interval; firmware filters remove any n-modulation frequency returns to provide a clean dataset devoid of this ambiguity. Modern phase-shift scanners improve the accuracy of the distance measurement by using more than one modulation wavelength, where the amplitude of the carrier wave is modulated to form two longer wavelengths (fig. 2B). This bootstrapping approach uses the longest modulation wavelength to determine a coarse distance and uses the intermediate wavelength to improve the distances measured to a point that there is no ambiguity on the shortest carrier wavelength and the highest accuracies can be obtained. 
The FARO is a class $3 \mathrm{R}$ laser system that operates at a 905 nanometer wavelength spectrum (FARO Technologies, Inc., 2013). This is a wavelength that contains a significant amount of interference for the sun during daylight hours, where the solar noise competes with the laser during bright sunny days, therefore decreasing the effective distance that the scanner is able to collect sufficiently dense point cloud data. To mitigate the diminishing data density at distance from the scanner associated with this solar effect, we ensured that the scanner locations did not exceed $20 \mathrm{~m}$ between adjacent setup locations.

The FARO Focus ${ }^{3 \mathrm{D}}$ workflow uses alignment spheres, printed checkerboard targets, or flat planes distributed within the field of view of adjacent instrument setup to align the T-Lidar imagery into one comprehensive dataset. We used up to six $7.25 \mathrm{~cm}$ and six $10.00 \mathrm{~cm}$ FARO spherical targets in any given scan distributed throughout the study site to align all of the scans collected in the survey. A fourtarget reference frame was initially established on the levee outside of the trench excavation area, where during subsequent surveys, the alignment spheres could be precisely repositioned in the same location for later alignments (fig. 3). The northernmost target was a $3 \mathrm{~cm}$ magnetic threaded screw that was installed into the paved levee crown, two were screwed into the trunk of a tree (later identified as unstable) and the southernmost target was a pole set up over an existing benchmark on the levee crown. The reference frame was expanded on the second survey after the trench excavation was complete, to include four new semi-permanent sites on the levee crown for alignment with the final survey. These also were threaded bolts that were screwed into the paved levee surface.

The same alignment-sphere sizes were placed on the reference target locations for each of the subsequent surveys to ensure a good alignment from one time period to the next. The remainder of the FARO spheres were treated as temporary alignment spheres (TAS) to increase the density of alignment spheres in adjacent scans during the same survey. When the scanner position exceeded approximately $25 \mathrm{~m}$ from a TAS, the sphere was relocated to a position where it could be easily seen in the next few scan locations. Moving the TAS positions provided a more balanced distribution of the spheres throughout the scan area to improve the 3D alignment (fig. 3). 
A

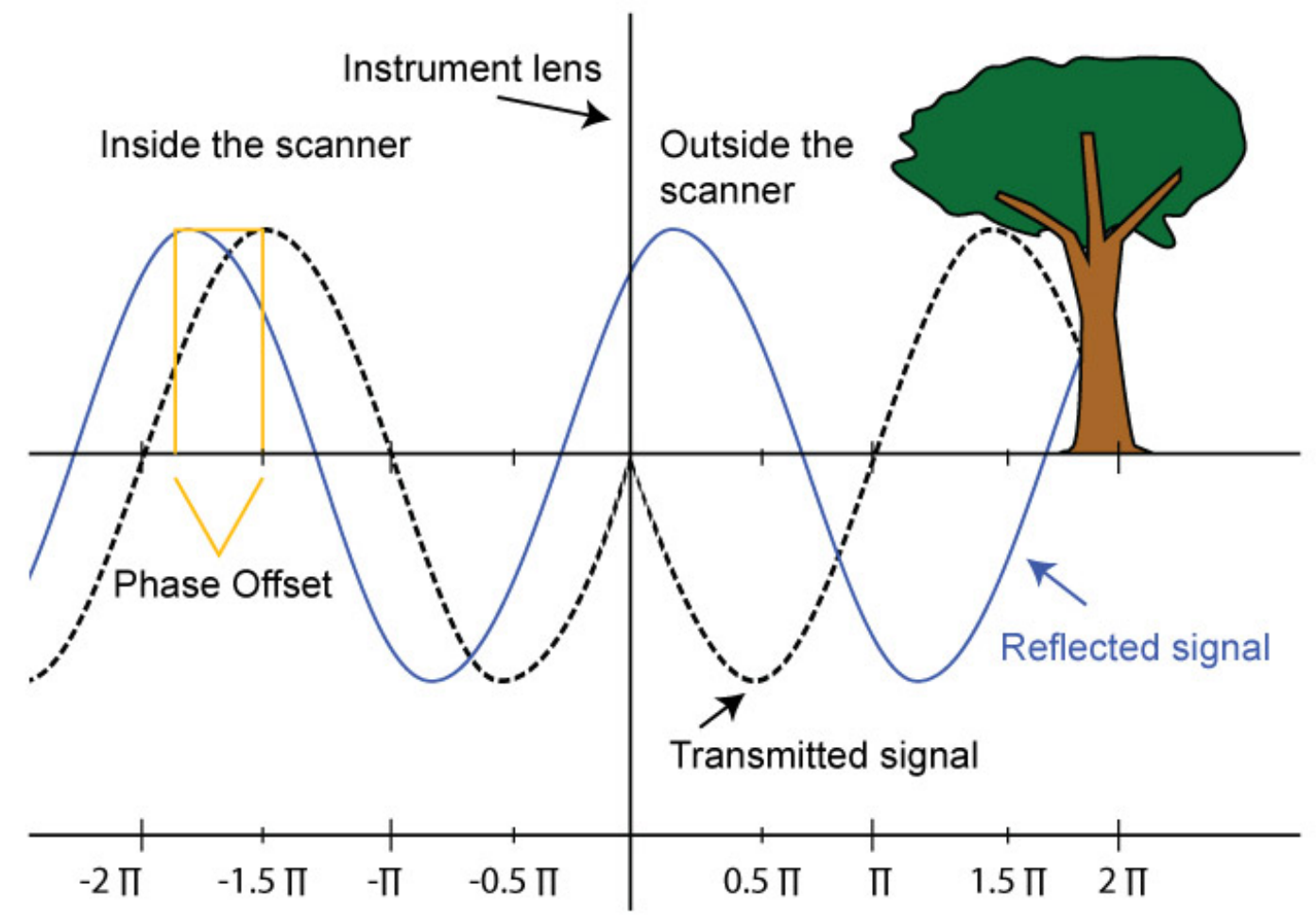

B

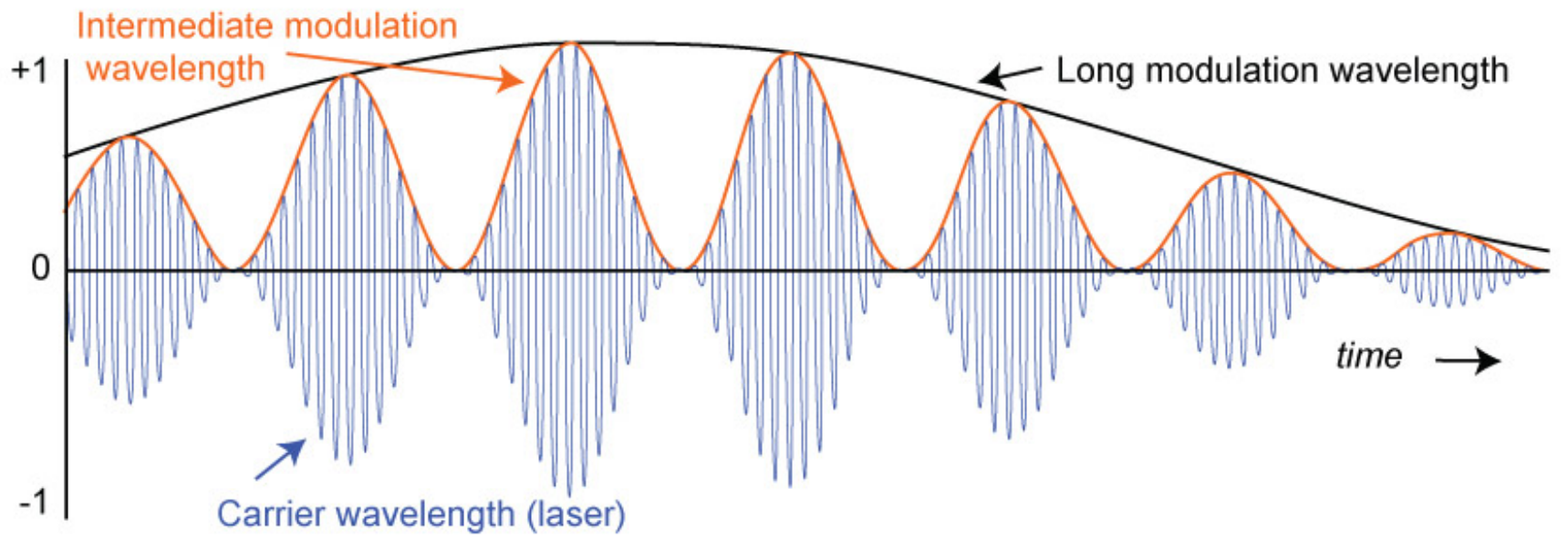

Figure 2. Schematic diagram showing phase shift and phase modulation. $(A)$ The transmitted signal (black, dashed sine wave) reflects off a target (tree) and returns to the scanner (blue sine wave). Inside the scanner, the reflected signal is matched with the waveform of the transmitted signal to measure the phase offset. Modified from FARO Technologies, Inc., 2012a. (B) The carrier wavelength (shortest wavelength in blue) is modulated from both an intermediate wavelength (orange) and a long modulation wavelength (black). Modified from Pfeifer and Briese (2008). 


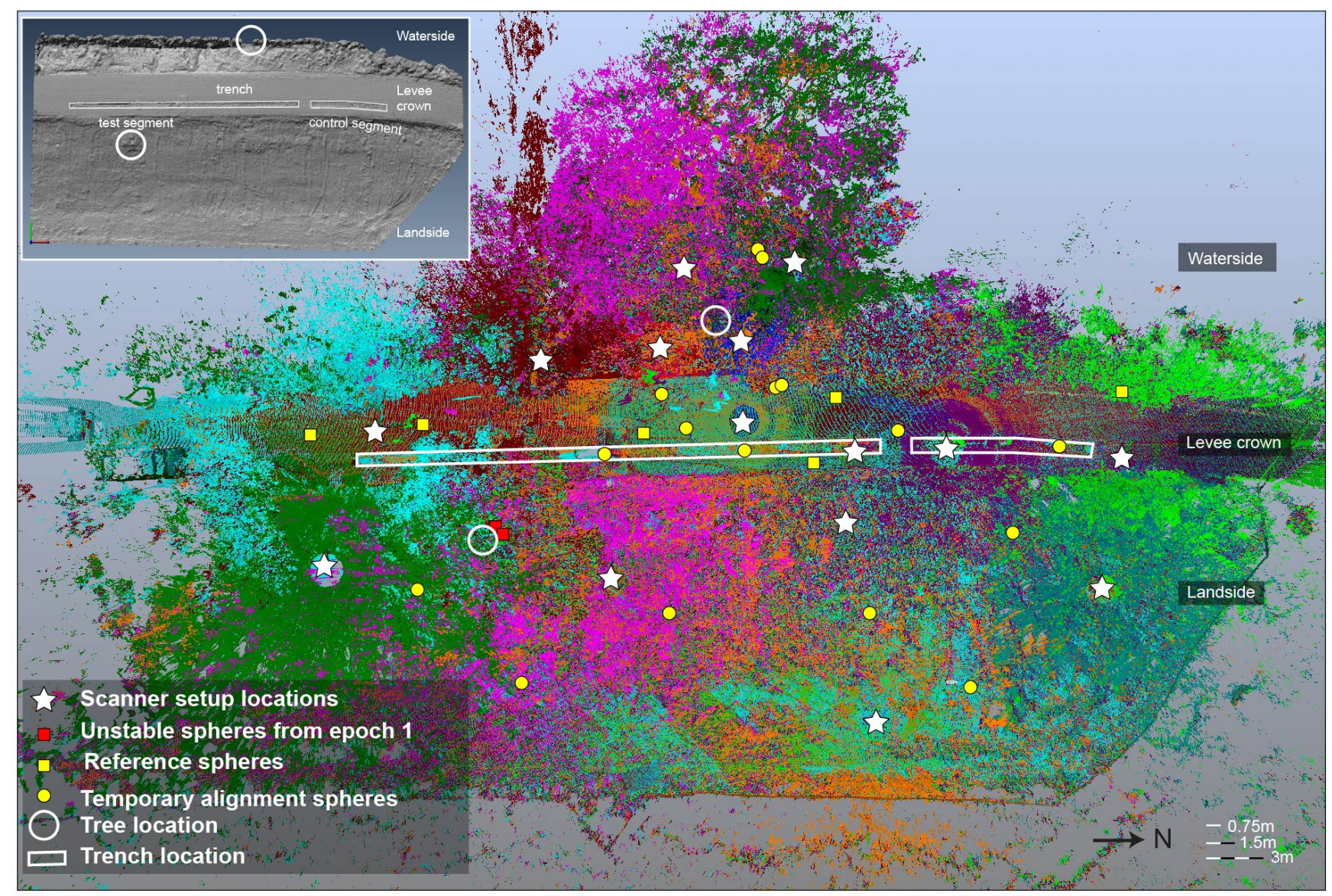

Figure 3. Example of terrestrial light detection and ranging point cloud map of the imaged levee (epoch 3) with scanner setup locations, reference frame sphere locations, and temporary alignment sphere locations. Each scan is shown as a different color with the scanner location shown as a star, with data (color points) extending radially outward from the star where data is not collected directly beneath the instrument. The inset in the upper left corner shows a gridded 2-centimeter shaded-relief, bare-earth digital elevation model of the levee surface with the trench location outlined in white. The map shows the two unstable reference spheres (red squares) and the other reference spheres that were used during the surveys (yellow squares). Additionally, the temporary alignment spheres (yellow circles) that only applied to the final survey are shown as distributed throughout the seepage test area. The trench location is outlined in white, with the smaller control segment to the north (right) and the longer test segment to the south (left). The white circles represent the locations of the two trees discussed in the report. Twitchell Island, California, 2012. (m, meter.) 


\section{Scan Alignment}

We initially used the FARO SCENE software to align all of the T-Lidar scans collected within each survey and to align the data collected in different epochs (FARO Technologies, Inc., 2012b). FARO SCENE automatically identifies the alignment spheres within a given scan and fits a best-fit 3D mathematical spherical primitive to the target; and, therefore is able to mathematically identify the center of the alignment sphere regardless from which direction the sphere was scanned. The same patterns of three or more spheres in two or more overlapping scans are recognized by the software and the 3D xyz positional relationship among the distributed spheres is used to initially rotate and translate the scans together into the same reference frame. A comprehensive alignment is then performed that minimizes the misfit of all overlapping alignment spheres within the dataset. Spheres that exceeded 25 $\mathrm{m}$ from the instrument often had insufficient data density to provide a robust target center position and were omitted for the alignment of the particular scan.

The four initial targets and the dual-axis compensator within the scanner where used to achieve a good internal alignment for epoch 1 . The additional reference and TAS spheres and the dual-axis compensator were used for the internal alignments for epochs 2 and 3 . However, alignment of the three surveys turned out to be difficult, as three of the four targets of the baseline survey were unstable and could not be used to align with the subsequent two epochs; therefore, we used a surface alignment approach to register all three surveys together (discussed later in this report).

We used the 3D virtual reality software developed by the University of California Davis KeckCAVES LidarViewer (Kreylos and others, 2008) to scrutinize all of the scan alignmentsinternally within a given survey and among each of the surveys when aligned together. The LidarViewer software visualization package allowed us to assess the alignment quality of each of the scans and sets of scans by color coding each scan and using active-sync 3D stereo glasses to view the data in true 3D so that centimeter misalignments could be identified and corrected. LidarViewer also allowed us to visualize the point cloud data and directly measure the motion/feature offsets between each epoch. Two examples of LidarViewer images are provided in figure 4 and show: (1) a colorized 3D point cloud image of the trench with alignment spheres, and (2) the toppled tree on the water side where the initial baseline data are in white and the final survey is colorized; the figure can be viewed with red/blue 3D anaglyph glasses to visualize the point cloud in 3D (fig. 4). 

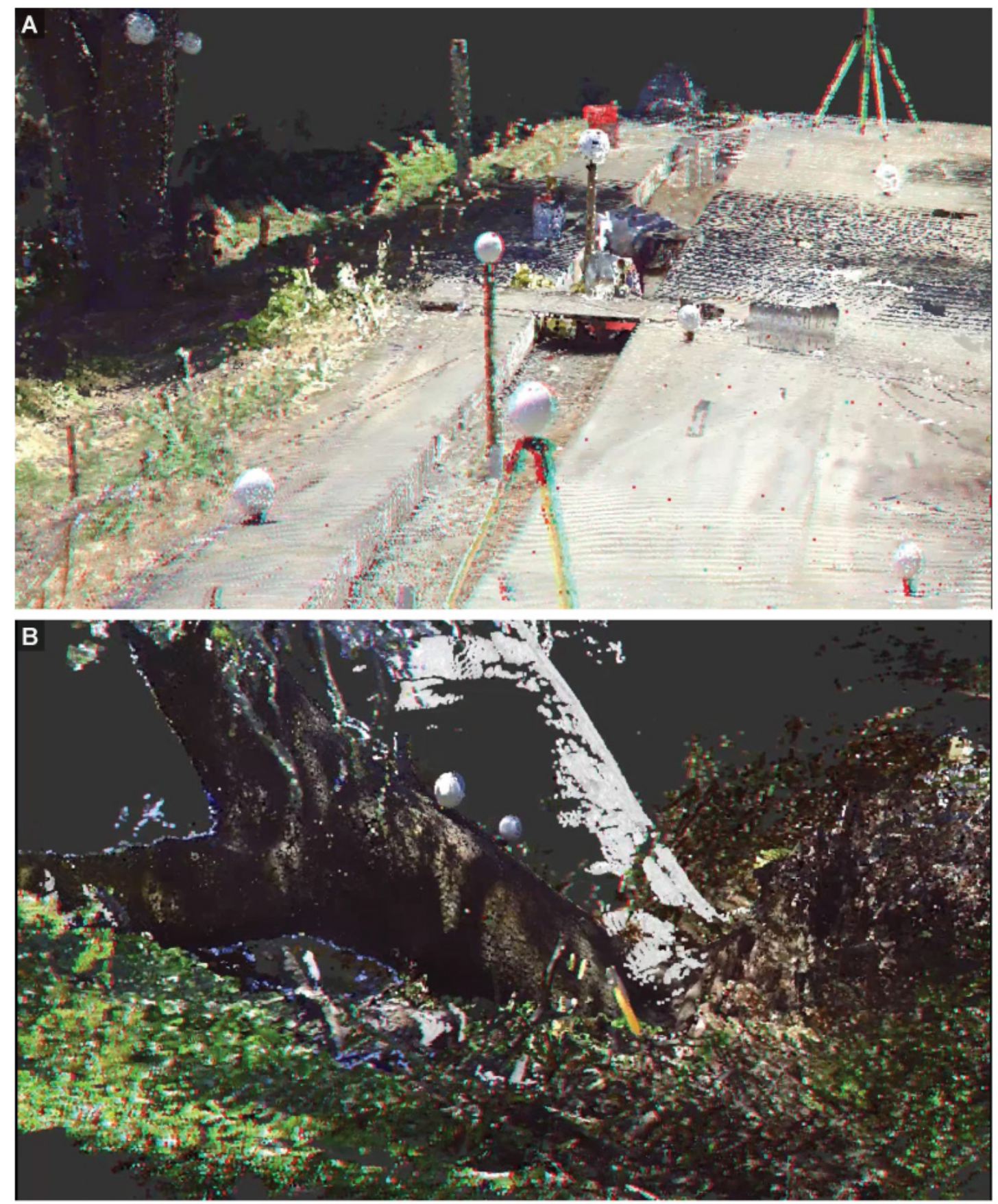

Figure 4. Three-dimensional anaglyph visualization of the point cloud data of $(A)$ the levee crown, alignment spheres, and seepage trench image; and $(B)$ the tilted waterside tree with white points showing the initial position of the tree and the colorized point cloud showing the data collected at the end of the project. Twitchell Island, California, 2012. Use red/blue anaglyph glasses for best viewing of the figure. 
During our alignment assessment, we realize that the errors between sphere center points were larger than expected from the standard errors expected from the FARO laser scanner. We attempted numerous alignment iterations using all of the reference spheres, including those located on the landside tree, but the RMS scatter of the reference sphere center points were much larger than anticipated, ranging from 1.5 to $3 \mathrm{~cm}$. In FARO SCENE alignment software, there is no way to visually inspect the data to assess possible error sources. The software solely relies on the mathematical alignment of the given targets. However, when the point cloud was visualized in 3D with LidarViewer during our quality control assessment, many unsatisfactory alignment artifacts became apparent, including a 5-cm offset between scans of the trench wall in the final survey and the outline of the trench cut into the pavement in the baseline survey. There also were far-field vertical offsets ranging from 1 to $5 \mathrm{~cm}$ at the far southwestern and northeastern ends of the levee, and an offset in two far-field trees thought to be stable, because they were outside of the study area. The tree on the landside of the levee with the two reference spheres showed rotation towards to the levee crown, which is counterintuitive based on the tree center of mass leaning towards the landside. However, with further inspection, the rotation was consistent with a shift of the complete dataset towards the levee crown with a pivot location above the ground surface on the tree. After the waterside tree toppled, the UCB team questioned the stability of the landside tree and established a simple string extensometer that measured approximately $1 \mathrm{~cm}$ of motion by the end of the survey.

Based on the field observations and the fact that the alignment of the baseline survey to the subsequent surveys produced alignment artifacts, we used PolyWorks ${ }^{\circledR}$ IM Align module (InnovMetric Software, Inc., 2013), which fits a surface to the point clouds and then uses a best-fit algorithm alignment method to align the baseline survey to the final survey, which in our case was the most comprehensive and reliable dataset. In this alignment, we excluded point cloud data in both surveys for regions where there was observed motion: the area of the toppled tree; the tree on the landside that had observed motion through the string extensometer measurement; and the immediate area around the trench, but used an otherwise unaltered point cloud with vegetation included. Since the coverage of the landside levee flank was very sparse for the first survey, we felt confident that most of the surface alignment was achieved through matching the non-excluded parts on the concrete levee crown. We relied on the assumption that overall the levee top was stable and that by choosing an iterative alignment algorithm, subtle changes would, (and did) become visible on the levee top surface. We could not completely rule out that potential small-scale changes were masked by the alignment process, but we were able to identify and visualize that there was (at least relative) observed subsidence on the levee top. The RMS misfits of the alignments were very good with an average of 1.6, 3.1, and $3.1 \mathrm{~mm}$ for epochs 1, 2, and 3, respectively; and 2.9 $\pm 0.1 \mathrm{~mm}$ RMS misfit for each of the epochs combined (table 1). Epoch 2 was aligned to epoch 3 through FARO SCENE target-based alignment as the two surveys were only 2 weeks apart and had enough targets in common to achieve a good alignment. The unstable target spheres on the landside tree were excluded. The target center point alignment scatter was within the expected error range. 


\section{Key T-Lidar Methodological Approaches from This Study}

- When scanning linear targets, such as a levee or fault scarp, it is best to place one or more alignment spheres beyond the endmost location of the T-Lidar system at both ends of the linear target and ensure that the target is scanned from at least two instrument setup locations. This process ensures that endmost scans have sufficient geodetic control beyond the setup location and avoids possible tilting of the endmost scan when all of the alignment spheres are only located on one side of the scanner. Ideally, all of the alignment sphere/targets should be distributed on all sides of the scanner such that the azimuthal gap (angle between adjacent alignment targets seen by the scanner) does not exceed 135 degrees, preferably a maximum azimuthal gap of less than 90 degrees (Keightley and Bawden, 2010). The baseline survey had an azimuthal gap of 175 degrees at the southern end where there were no alignment spheres that extended beyond our endmost instrument setup - this resulted in an excess of $5 \mathrm{~cm}$ horizontal and vertical misalignment in the far field. We used the Polyworks IM Align module to mitigate this misalignment, a methodology that minimizes the misfit of the point cloud data among overlapping scans (see previous discussion in Scan Alignment section).

- The point-averaging data collection option that is now available on many T-Lidar systems can considerably reduce point cloud scatter within the datasets which makes it possible to measure sub-centimeter scale surface changes without reducing the data to mathematical primitives (that is, points, planes, cylinders, and cones). We determined that 4-point averaging considerably improved the data quality without unnecessarily extending the time required to finish the project. The point cloud scatter was approximately $1.4 \mathrm{~mm}$ for a flat target using 4-point averaging as compared with about $8 \mathrm{~mm}$ of scatter associated with using no-point averaging.

- When using alignment targets with a FARO scanner, the maximum target distances should not exceed $20 \mathrm{~m}$ for a $7.5 \mathrm{~cm}$ sphere and $25 \mathrm{~m}$ for a $10 \mathrm{~cm}$ sphere when using 4-point averaging. This is to ensure that the point cloud density on the targets is sufficient during daylight hours to be useful for sub-centimeter dataset alignments.

- Using a 3D visualization environment (KeckCAVES, LidarViewer) was necessary to recognize and correct sub-centimeter misalignments from adjacent scans that were not possible by simply evaluating the statistical analysis provided by both FARO SCENE and Polyworks IM Align module. LidarViewer allowed us to recognize potential alignment issues, identify the possible sources of the misalignment, and then ultimately correct the alignment using the software. This iterative process considerably improved the quality of the alignments such that there was subcentimeter point scatter along the levee crown outside the area that subsided between the first and last survey. 


\section{Results}

\section{Change Detection Analysis}

We analyzed four areas in the point cloud imagery to detect changes: (1) the waterside tree that rotated during the seepage test; (2) the landside tree; (3) the unobstructed paved surface of the levee crown; and (4) regions on the landside levee bank devoid of vegetation. The change detection graphics shown in this section were generated by differencing the point cloud data for each epoch against a mesh of the previous data along one of the major axes (levee parallel, perpendicular or vertical) or as the shortest distance; a descript of the different T-Lidar differencing approaches and their error sources can be found in Lague and others (2013). This is accomplished by differencing the 3D point position (xyz) along a given axis and recording the positional change for each point in the dataset. The shortest distance is obtained by determining the closest 3D point in the initial time period (reference dataset) that corresponds to the closest point in the second time period. We used PolyWorks software for the change detection calculations, angular change, and positional measurements (InnovMetric Software, Inc., 2013). The measurements were then verified using the 3D virtual reality LidarViewer software (Kreylos and others, 2008).

\section{Waterside Tree}

Midway through the seepage test, the large tree located on the waterside of the levee toppled over into the water behind the levee (fig. $4 B$ ) and generated a series of cracks on the levee bank. Fresh fractures/cracks formed on the paved levee crown in the hours and days after the tree toppled. Our analysis determined that the trunk of the tree rotated towards and into the water by 20.67 degrees with a minor levee parallel motion in the rotation (fig. 5). The rotation was calculated by fitting a best-fit cylinder primitive (primitive - a mathematic geometric feature, such as points, vectors, polylines, planes and cylinders) to each of the tree trunks along a corresponding straight section of the tree in each epoch. The cylinders were then extended to determine their intersection, thereby determining the $3 \mathrm{D}$ rotation vertex location (angle vertex on fig. 5). The rotation magnitude was determined by measuring the angular relationship of the centerline vectors within each of the cylinder primitives using the cylinder vector intersection as the tree rotational vertex. 


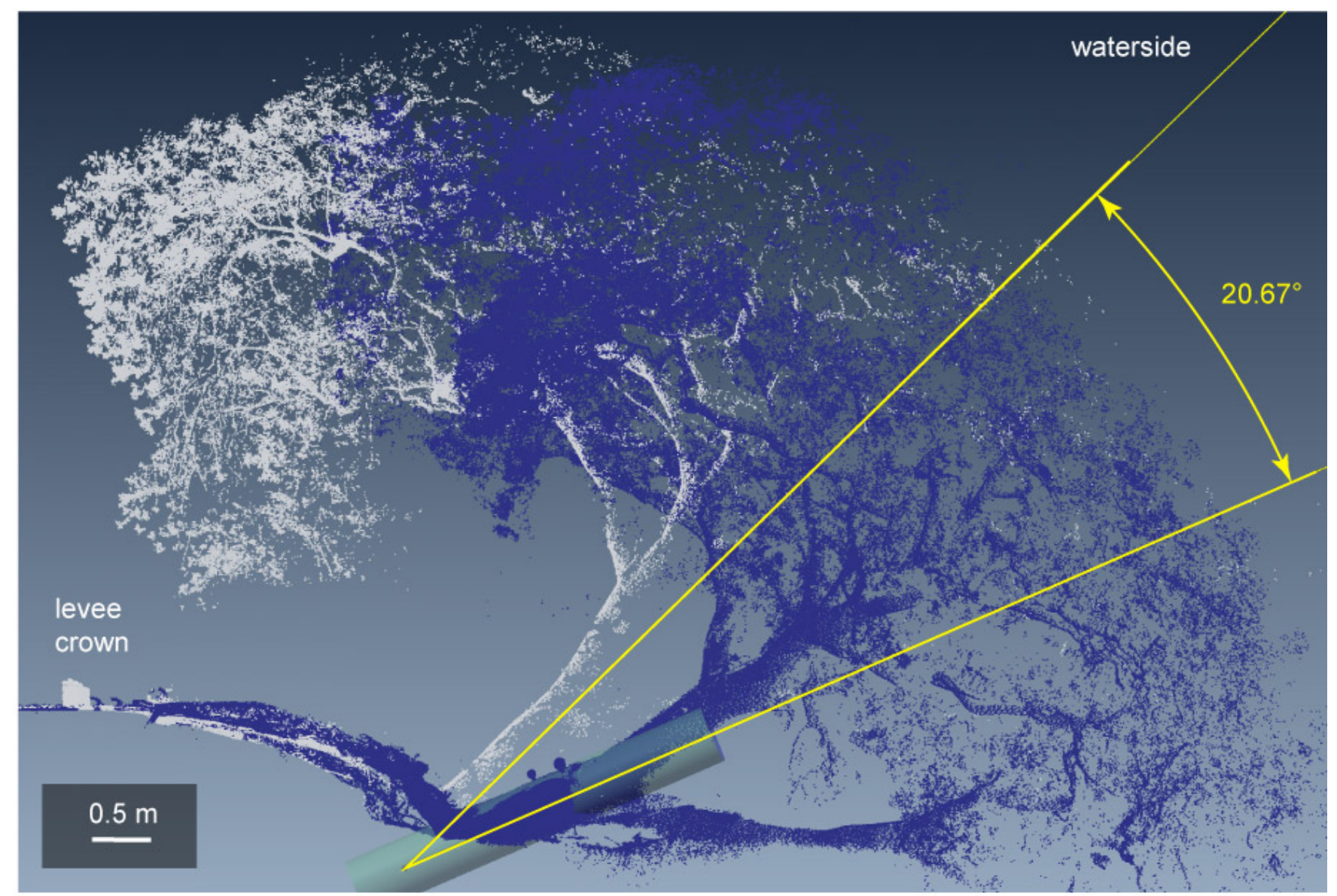

Figure 5. Point-cloud imagery shows 20.67 degrees of rotation of the waterside tree from the pre-seepage test scan on April 4, 2012, (white) and the final survey on June 6, 2012, (blue) with the best-fit cylinder for the June dataset. Twitchell Island, California, 2012. 


\section{Landside Tree}

Assessing the stability of the landslide tree was important because our initial reference frame was anchored to the tree and had two alignment spheres attached which where scanned in every survey. Therefore, any motion (rotation) of the tree automatically resulted in misalignments with subsequent surveys. Once we recognized that the landside tree had shifted the reference frame, we removed these spheres from the alignment process so we could track positional changes along the tree trunk. Between April 4 and June 6,2012 (the first and final survey), we determined that the tree rotated towards the landside about $5 \mathrm{~cm}$ at a tree height of $2 \mathrm{~m}$ (fig. 6A) and can be seen as increased displacement in the tree position from the ground upward. Between May 29 and June 6, 2012, (second and final surveys) there was about $1 \mathrm{~cm}$ of motion; therefore, the majority of the tree motion took place between April 4 and May 29- the first and second survey (fig. 6). The UCB string extensometer placed on the landside tree after the waterside tree toppled showed just less than $1 \mathrm{~cm}$ of landward motion, which is in good agreement with our measurement between our second and final surveys.
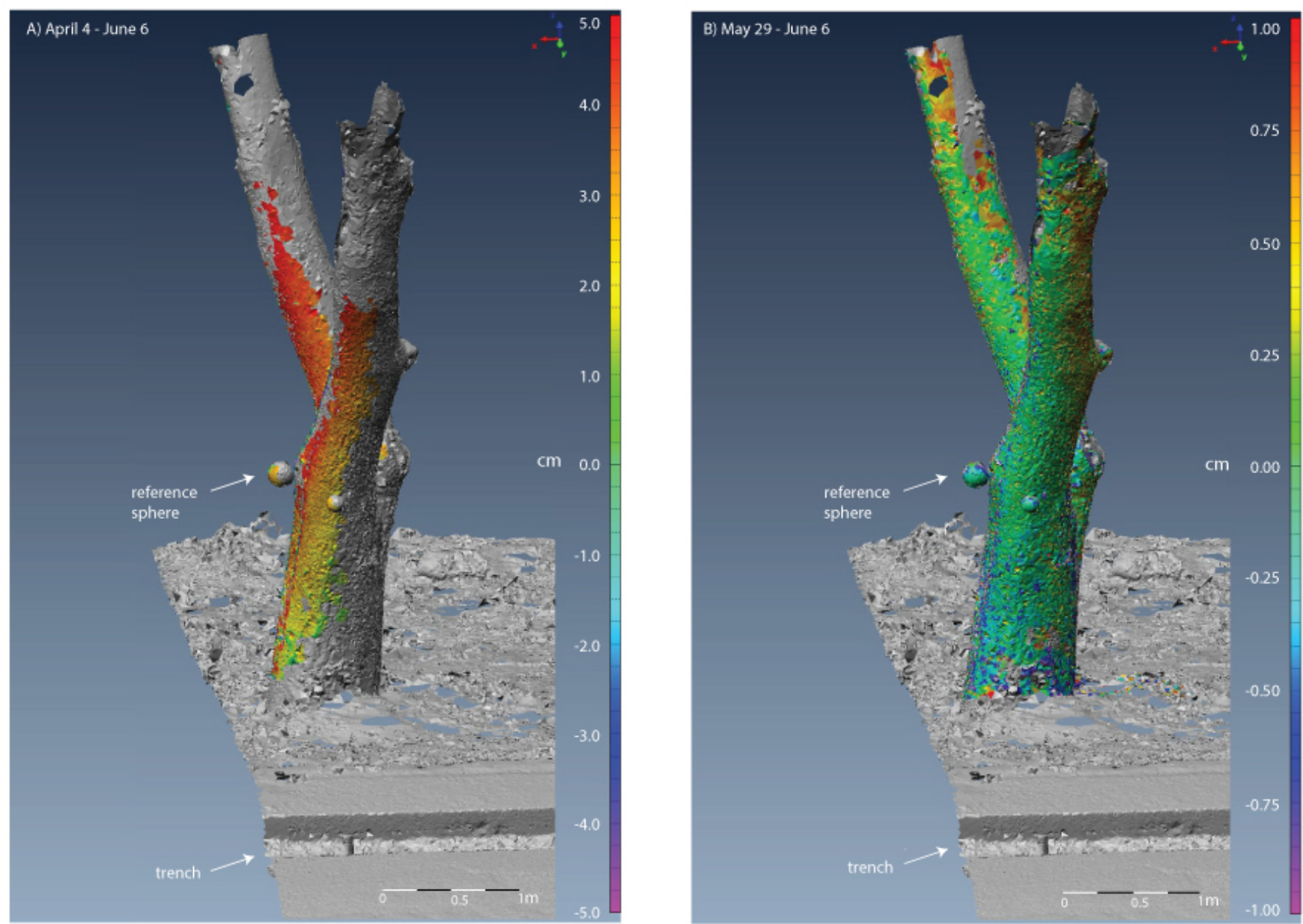

Figure 6. Difference map showing displacement pattern on the landside tree between (A) April 4-June 6, 2012, and (B) May 29-June 6, 2012, Twitchell Island, California. Note that the color scales are not the same in both images. The scale is larger in $(B)$ to show smaller displacement along the $y$-axis (perpendicular to the levee) that occurred between the second and final survey. Twitchell Island, California, 2012. 


\section{Levee Crown}

The waterside tree failure produced noticeable cracks in the paved levee crown, including a crack that formed on the northern lateral wall of the trench with approximately $1 \mathrm{~cm}$ of observable differential motion with the waterside subsidence (fig. 7) measured at the break between the control trench and the test trench. The levee crown is a very lightly traveled abandoned asphalt road surface that spans the width of the levee. We produced a difference map of the crown showing the location and extent of the subsided region (fig. 8) by comparing the first epoch to a mesh of the last epoch along the $\mathrm{Z}$-axis. We located three regions on the levee crown that showed vertical motion (Labeled X, Y, and Z on fig. $8 A-B$ ). The northernmost region (area $\mathrm{X}$ ) associated with the crack caused by the subsidence is approximately $1.3 \mathrm{~m}$ wide and $15.8 \mathrm{~m}$ long with a maximum subsidence of $2.1 \mathrm{~cm}$ (fig. $8 B-C$ ). The central region (area Y) is a semicircular feature, $3.4 \mathrm{~m}$ wide and $11.2 \mathrm{~m}$ long with the maximum subsidence magnitude of $6.25 \mathrm{~cm}$ located near the waterside of the trench. The southernmost subsidence feature (area $\mathrm{Z}$ ) parallels the waterside trench and is $1.4 \mathrm{~m}$ wide and $8.2 \mathrm{~m}$ long with a maximum subsidence of $3.5 \mathrm{~cm}$. It must be noted that because our initial survey occurred before the trench was excavated, we cannot resolve the exact timing of the subsidence; specifically, whether these features are associated with the trench construction, the seepage test, or the waterside tree fall. A high frequency TLidar scanning approach would have been required to constrain the temporal and spatial variability of the levee throughout the full seepage test experiment. We noted that there is an area of uplift about 1.5 $\mathrm{cm}$ located on the waterside of the levee between the $\mathrm{Y}$ and $\mathrm{Z}$ shown on the figure $8 B-C$. This feature was recognized months after the experiment had concluded, therefore it was not possible to verify, in the field, the observations and explore possible deformation sources. Another area of apparent uplift is the red levee parallel feature near $\mathrm{X}$ on figure $8 B-C$ was determined to be straw wattles used during the seepage test that were not in the initial baseline survey. 

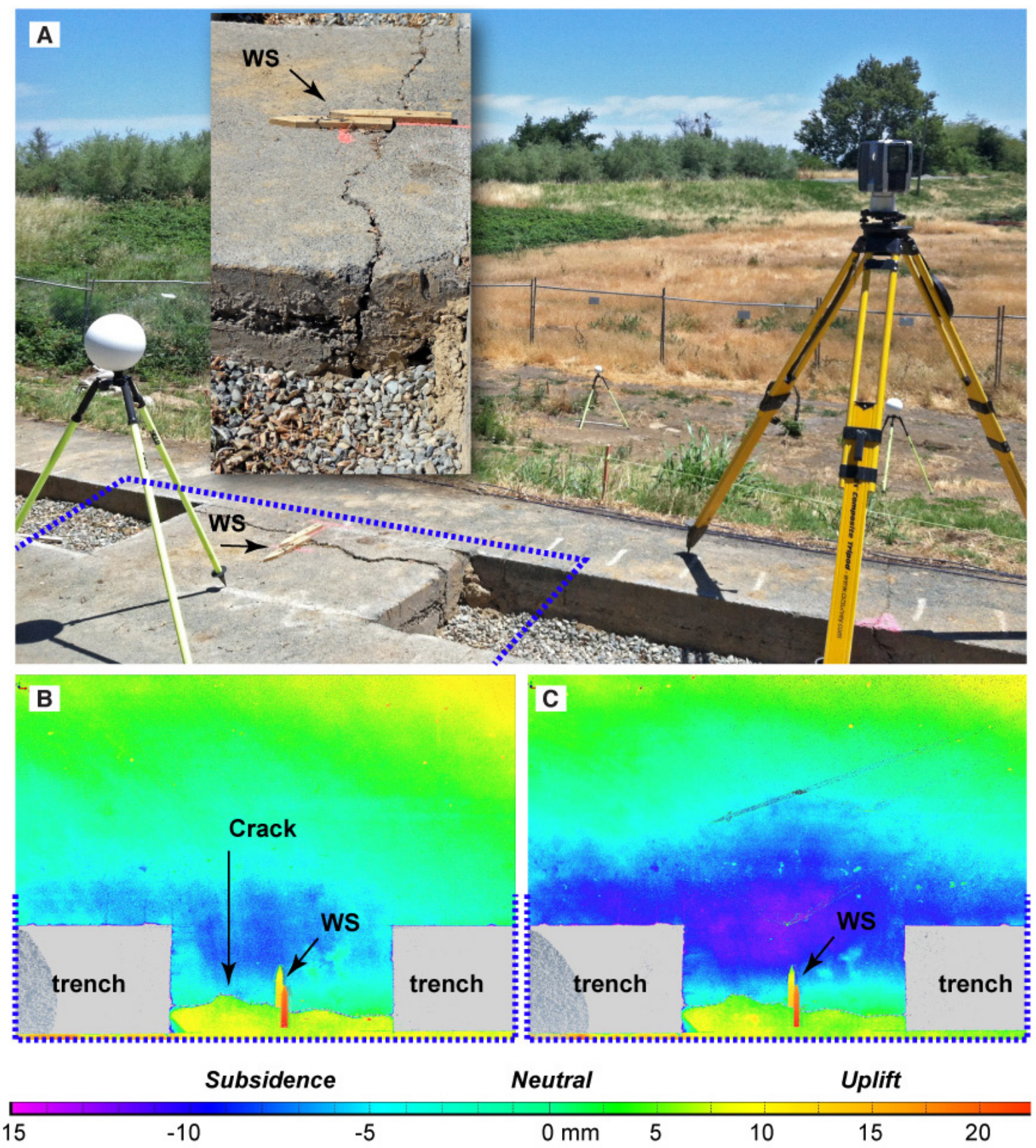

Figure 7. Photograph of $(A)$ the laser scanner imaging a prominent crack in a connecting wall at the northern end of the primary seepage trench and elevational difference maps across the crack from (B) April 9-May 29, 2012, and $(C)$ April 9-June 6, 2012, Twitchell Island, California. The view of $(B)$ and $(C)$ is looking from the landside of the levee with the wood stakes (WS) in the lower center and the trench floor in gray; the location of $(B)$ and $(C)$ is represented as the blue dashed line in $(A)$ and on the corresponding parts of $(B)$ and $(C)$ The photograph does not span the full area represented in $[B]$ and $[C]$. The inset shows a close view of the crack as viewed from near the scanner location. Note that the scale is non-linear; it was optimized to show the wood stakes and the localized subsidence. Twitchell Island, California, 2012. (Photographs $[A]$ and inset both taken June 6, 2012, by Sandra Bond and Gerald Bawden, respectively.) 

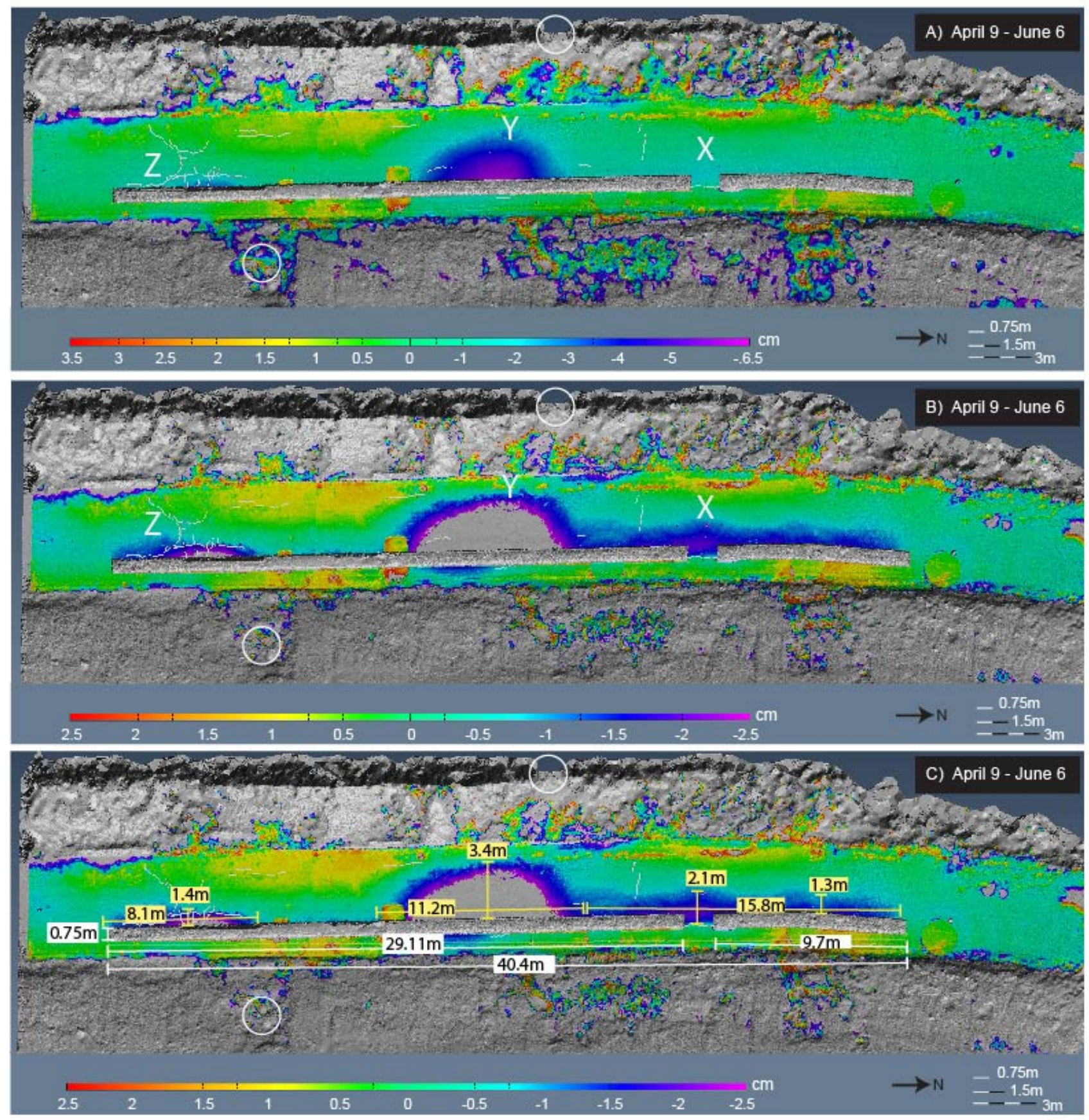

Figure 8. Colorized vertical change map focusing on the levee crown, Twitchell Island, California, between April 9 and June 6, 2012. Colors show the magnitude of elevational change between the two time periods in centimeters $(\mathrm{cm})$. Areas of gray either have insufficient data between the two time periods or the magnitude of the motion exceeds the scale range for the figure. $(A)$ Optimized to show the full range of motion on the levee crown and $(B)$ Optimized to show small-scale elevational changes on the levee crown between 2.5 and $-2.5 \mathrm{~cm}$, where the gray areas on the levee crown that are colorized in $(A)$ exceed the scale range. $X, Y$, and $Z$ are subsidence areas discussed in the report and the white lines are mapped small scale fractures/cracks. $(C)$ Shows the physical measurements of the trench (white) and the extent of the subsidence features on the paved levee crown (yellow), the elevational changes are shown the same as in $(B)$. Twitchell Island, California, 2012. (m, meter.) 


\section{Landside Levee Flank}

We created bare-earth models of the landside levee flank for each epoch to assess if there was detectable motion, especially in areas where there were water seeps. The landside levee flank was not cleared of vegetation (mostly grasses) during our first survey; as a consequence, the laser scanner was not able to fully penetrate the dense vegetation and image the land surface so we could measure surface elevation changes associated with the seepage test. Therefore, we could only get a measurement for changes between the second and final surveys, because much of the vegetation had been removed by that time. We used the TerraScan ${ }^{\mathrm{TM}}$ software to identify the remaining vegetation in the point cloud data on the landside of the levee, remove it from the dataset (Terrasolid Ltd., 2013), and create a gridded 5$\mathrm{cm}$ bare-earth $\left(25 \mathrm{~cm}^{2}\right.$ grid size $)$ DEM of the levee crown and landside levee flank. We then differenced the DEMs along the z-axis for each of the epochs to resolve possible vertical motion along the levee flanks (fig. 9). We found no vertical motion that exceeded $5 \mathrm{~cm}$ between May 29 and June 6, 2012, on the landside levee flank. There are some localized areas of $-2 \mathrm{~cm}$ vertical change (blue; fig. 9) that are likely associated with vegetation changes on the levee. The east-west feature spanning the trench in the middle of the trench that shifts from 3 to $-3 \mathrm{~cm}$ (orange/blue; fig. 9) is a piece of plywood that was moved sometime during the week between surveys. The band of yellow $/$ red $(3-5 \mathrm{~cm}$; fig. 9$)$ on the waterside of the levee crown is associated with debris that was swept to the side of the levee.

Table 2. TerraScan ${ }^{\mathrm{TM}}$ parameters used to classify (a-upper) ground points and (b-lower) vegetation points, Twitchell Island, California, 2012.

[Extracted bare-earth surface model is classified ground points +0.05 meter $(\mathrm{m})$ buffer. The parameters were optimized to remove the grasses/vegetation while retaining the shape edges of the trench wall. Parameter definitions from Terrasolid Ltd. (2013)]

\begin{tabular}{|c|c|c|c|c|c|}
\hline $\begin{array}{l}\text { Max building size } \\
\text { (m) }\end{array}$ & Terrain angle & Iteration angle & $\begin{array}{l}\text { Iteration distance } \\
\text { (m) }\end{array}$ & $\begin{array}{l}\text { Reduce iteration } \\
\text { angle when edge } \\
\text { length less than } \\
\text { (m) }\end{array}$ & $\begin{array}{c}\text { Stop } \\
\text { triangulation } \\
\text { when edge } \\
\text { length less than } \\
\text { (m) }\end{array}$ \\
\hline 5.0 & 89.00 & 50.00 & 0.2 & 0.5 & 2.0 \\
\hline \multicolumn{2}{|c|}{ Ground class maximum triangle $(\mathrm{m})$} & \multicolumn{2}{|c|}{ Minimum height (m) } & \multicolumn{2}{|c|}{ Maximum height (m) } \\
\hline \multicolumn{2}{|c|}{10} & \multicolumn{2}{|c|}{0.05} & \multicolumn{2}{|c|}{100} \\
\hline
\end{tabular}




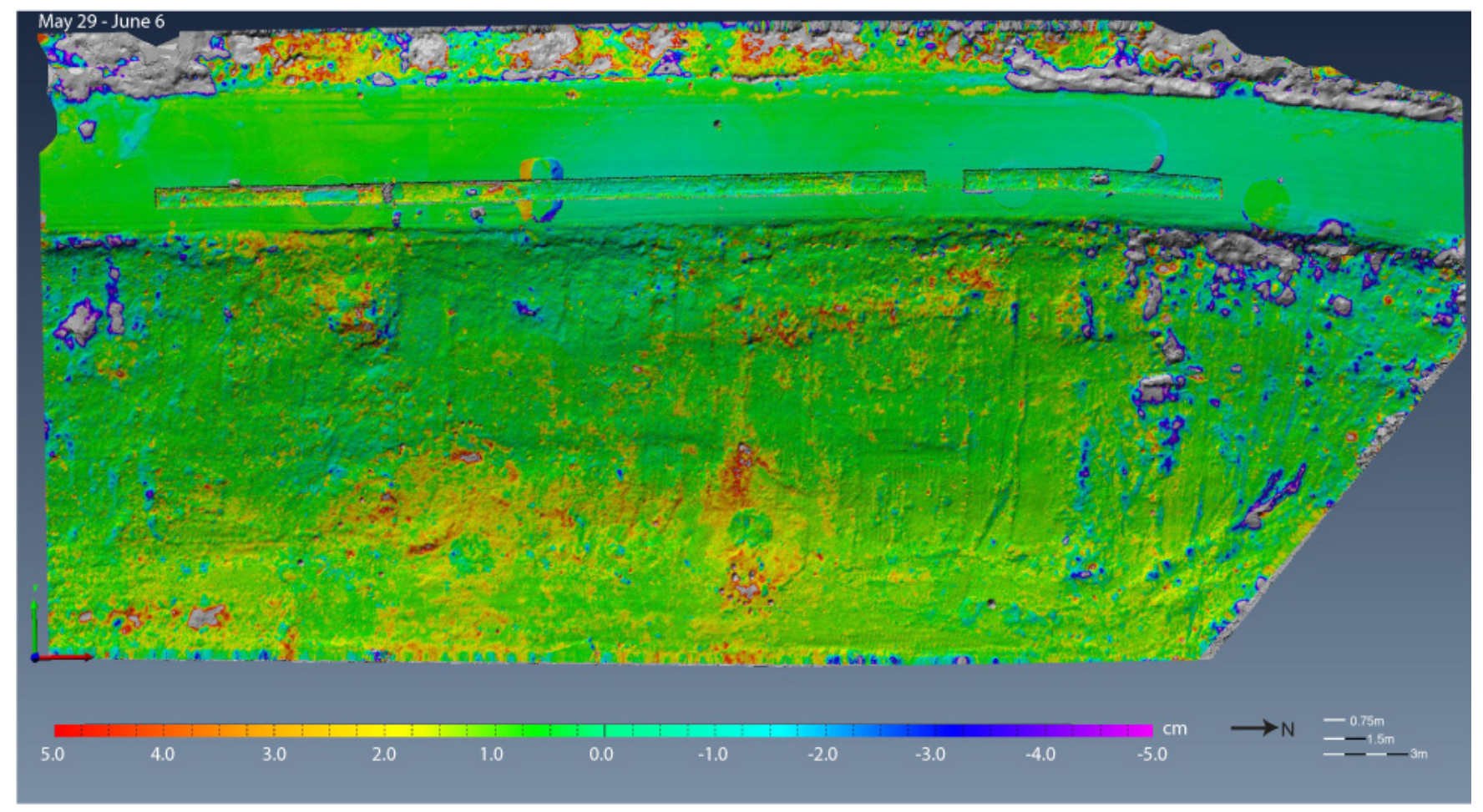

Figure 9. Difference map showing \pm 5.0 centimeters $(\mathrm{cm})$ of vertical change on the levee flank and crown, Twitchell Island, California, between May 29 and June 6, 2012. Red shows an increase in surface elevation between the two time periods where blue shows a decrease in elevation. The base map is a 5-cm bare-earth digital elevation model of the levee flank. Twitchell Island, California, 2012.

\section{Crack Mapping}

There were two sets of fractures on the levee: a set that predated the seepage test and a new set of fractures that formed during the test, most notably following the tree failure. The pretest asphalt had many cracks that were consistent with an aging surface. However, new cracks developed in the road surface after the tree toppled. Since the concept of mapping the fractures was only discussed during the final hours of the last day of T-Lidar data collection, and fracture mapping was not a component of the project scope, we neither optimized the T-Lidar survey to uniquely map all of the cracks nor assigned a formation age to each of the cracks to fully relate the cracking to the seepage test. However, we were still able to identify and map small cracks and fractures that appeared on the levee in our data. Some of the active cracks associated with the seepage test were apparently old cracks that were reactivated during the seepage test (fig. 10), as evident from dead and dried vegetation predating the test. We only mapped the most observable cracks on the levee surface with T-Lidar 
We created a digital map of the major fractures in the asphalt-covered levee crown by evaluating subtle linear geomorphic expression of the cracks in the T-Lidar elevation data and by using the 3D RGB color component of the T-Lidar data to effectively map the cracks with assistance of the photographs (fig. 11). Relative elevational difference associated with the center of the crack, having a slightly lower height than the surrounding sides, creates a geomorphic quasi-linear feature that can be identified by differencing the point cloud data height and a best-fit plane that was fit through the surrounding point cloud data along the crack (fig. 11D). Areas along the fracture that had a lower relative elevation were identified and mapped using Polyworks Inspect module (InnovMetric Software, Inc., 2013). Additionally, many of the cracks were visible in the colorized point cloud data because they are slightly darker than the surrounding points, which allowed us to identify and map the cracks. A crack map of the levee crown shows that most of the major cracks were observed along the levee crown and on the immediate side of the levee near the fallen tree (fig. 8).
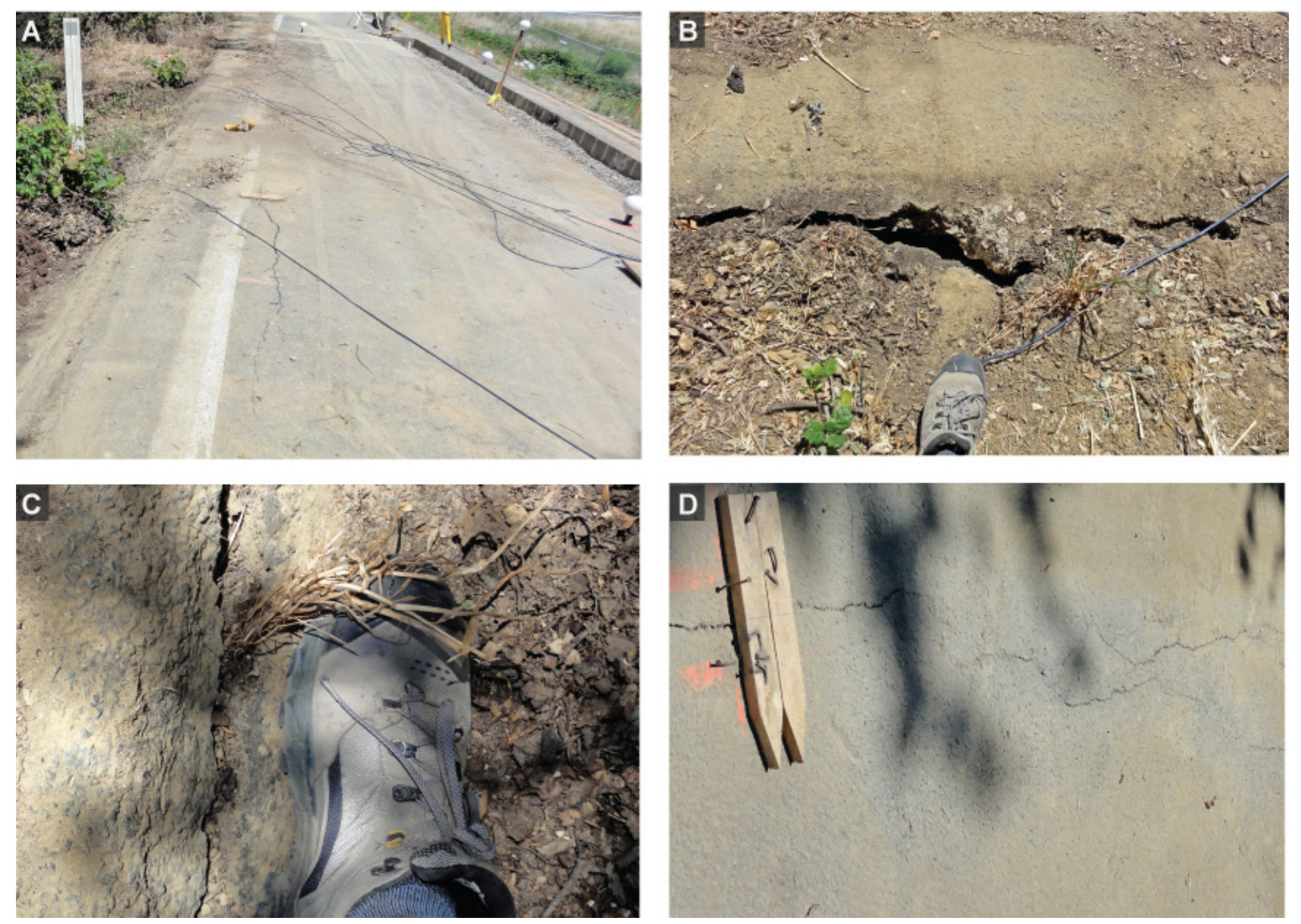

Figure 10. Photographs showing cracks on the levee crown, Twitchell Island, California, 2012. (A) An active crack located on the water side of the levee - note the debris on the levee surface; $(B)$ an active crack on the water side of the levee where a few centimeters of motion was observed and $(C)$ vegetation (now dead) was growing from the crack showing that the crack predated the seepage test but was reactivated during the test; and $(D)$ an active crack on the levee crown where wood stakes were attached to either side of the crack to measure additonal crack motion. Twitchell Island, California, 2012. (Photographs taken by Gerald Bawden, June 6, 2012). 

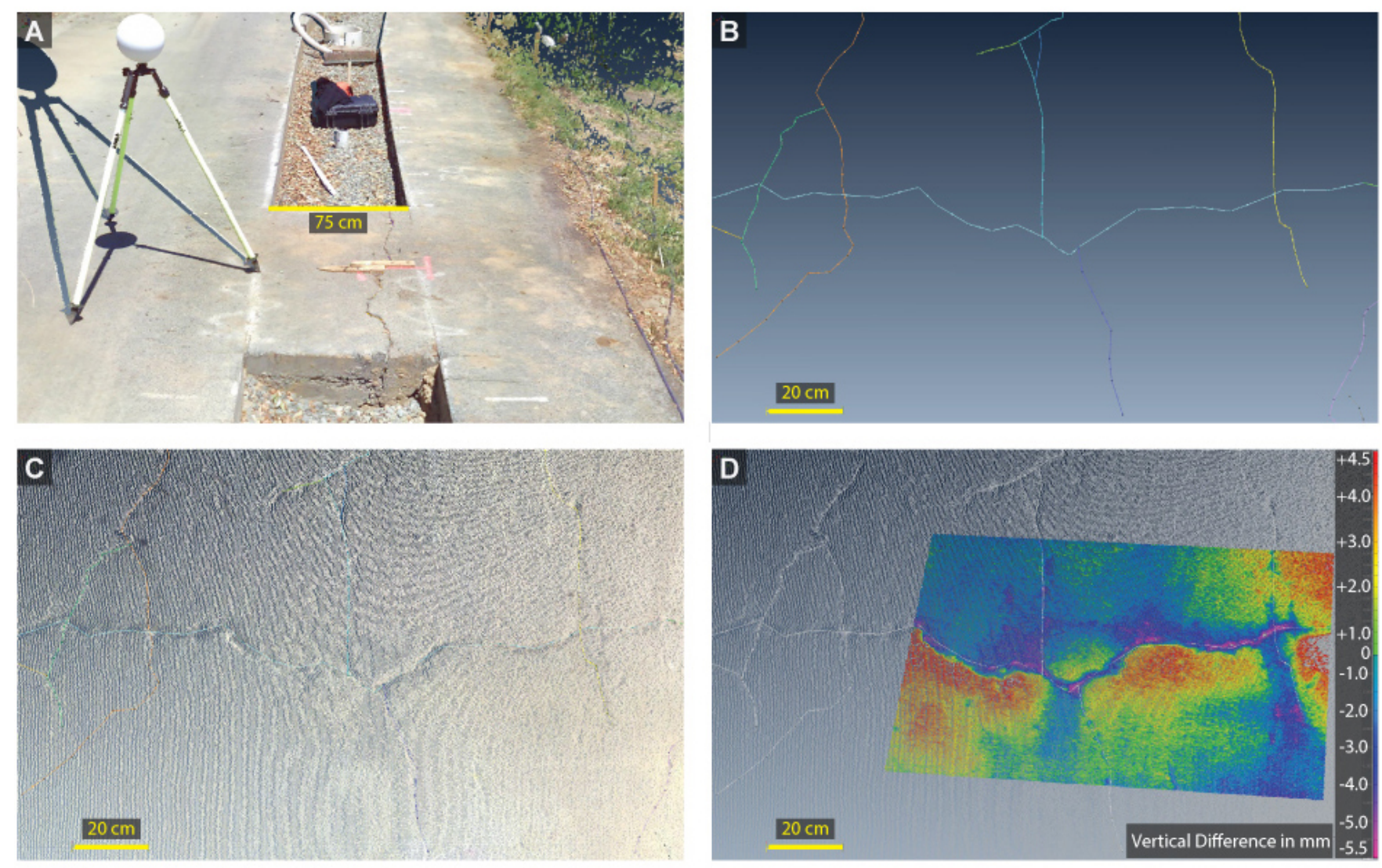

Figure 11. Terrestrial light detection and ranging (T-Lidar) analysis of cracks on the levee crown, Twitchell Island, California, 2012. (A) Shows a photo-quality colorized point cloud image from a single scan of the newly formed fracture connecting the two section of the levee seepage test where dark blue areas in the image are datagaps that are caused by object in the scanner field of view casting shadows (datagaps are in the upper right and behind the alignment sphere and a solar shadow is below the alignment sphere in the center of the image). This scan came from the T-Lidar setup shown in figure 7. (B) Shows mapped cracks on the levee surface from $(C)$ the point cloud data and from $(D)$ an elevation difference plot of the same area, where colored height differences from an averaged best-fit plane can easily identify the local height minimum (cool colors) from nearby high topography. The vertical difference scale in $(D)$ is in millimeters $(\mathrm{mm})$. Twitchell Island, California, 2012. 


\section{Landside Tree Characterization}

We used the T-Lidar imagery from the final survey to characterize the landside tree height, its cross sectional area parallel and perpendicular to the levee, and its canopy volume centroid. These biomorphic parameters were requested by the UCB team to be used in their analysis and computer modeling, which included assessing the wind footprint (cross-sectional area) of the landside tree on the levee. The landside tree height $(12.50 \mathrm{~m}$ ) was directly measured from the point cloud data (fig. 12) using the highest points at the top of the tree. The base of the tree was determined by defining the center of the tree trunk in the point cloud data where it intersects with a best-fit plane of the levee surface immediately surrounding the tree trunk. The tree centroid and cross-sectional area were calculated by creating a mesh from the outermost points in the scanned canopy (fig. 12) using Polyworks Inspect and IM Edit modules (InnovMetric Software Inc., 2013) — a methodology that has the appearance of digitally wrapping the tree with shrink-wrap that allows a few low data density branches to extend through the digital surface (fig. 13).

The levee parallel, perpendicular, and planar cross sections were determined by projecting the mesh derived from the canopy point cloud onto axis-parallel planes that are orthogonal to the levee (fig. 13). The levee parallel, perpendicular, and map view cross-sectional areas measured 101.6, 116.4, and $132.8 \mathrm{~m}^{2}$, respectively. Our mesh approach simplifies the overall shape of the tree canopy, which is effective for calculating the tree centroid (fig. 13). However, this approach does not measure 3D branch volume or diameter and, therefore, is insufficient to calculate the above-ground center of gravity for the tree. A T-Lidar survey targeting the tree's center of gravity would be needed to fully characterize the 3D canopy structure with a point cloud density sufficient to calculate the 3D distribution of the tree's above-ground biomass. 

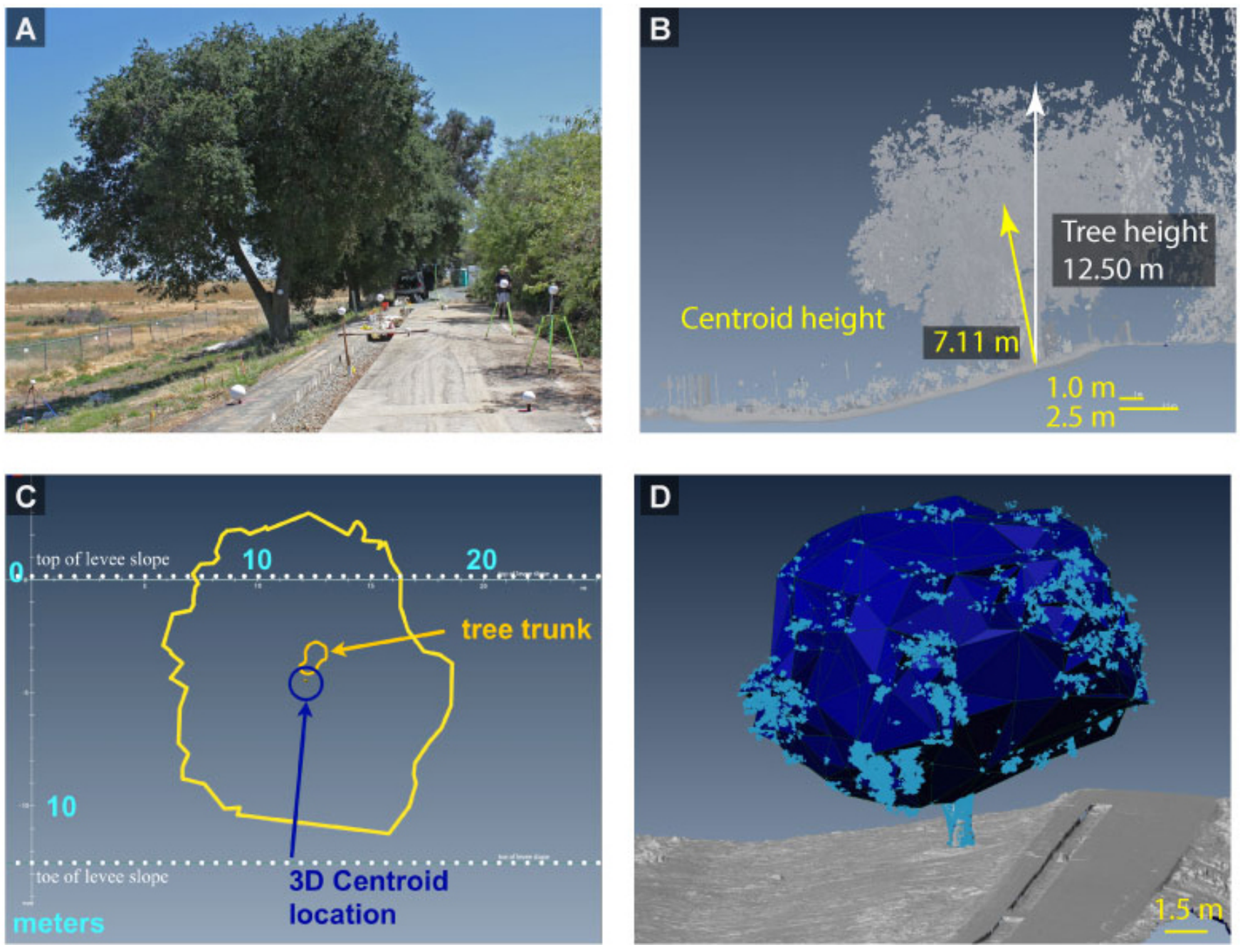

Figure 12. Characterization of the landside tree, Twitchell Island, California, 2012. (A) Photograph of the landside tree. $(B)$ The tree height (white) and centroid height (yellow) calculated from the point cloud data and related to the tree position on the levee flank. $(C)$ Map view of the locations of the tree trunk, canopy extent, and centroid. $(D)$ The mesh (dark blue surface) with point cloud data (cyan) on a 2-centimeter bare-earth digital elevation model (gray) of the levee. Twitchell Island, California, 2012. (m, meter; photograph taken by Sandra Bond, June 6, 2012.) 


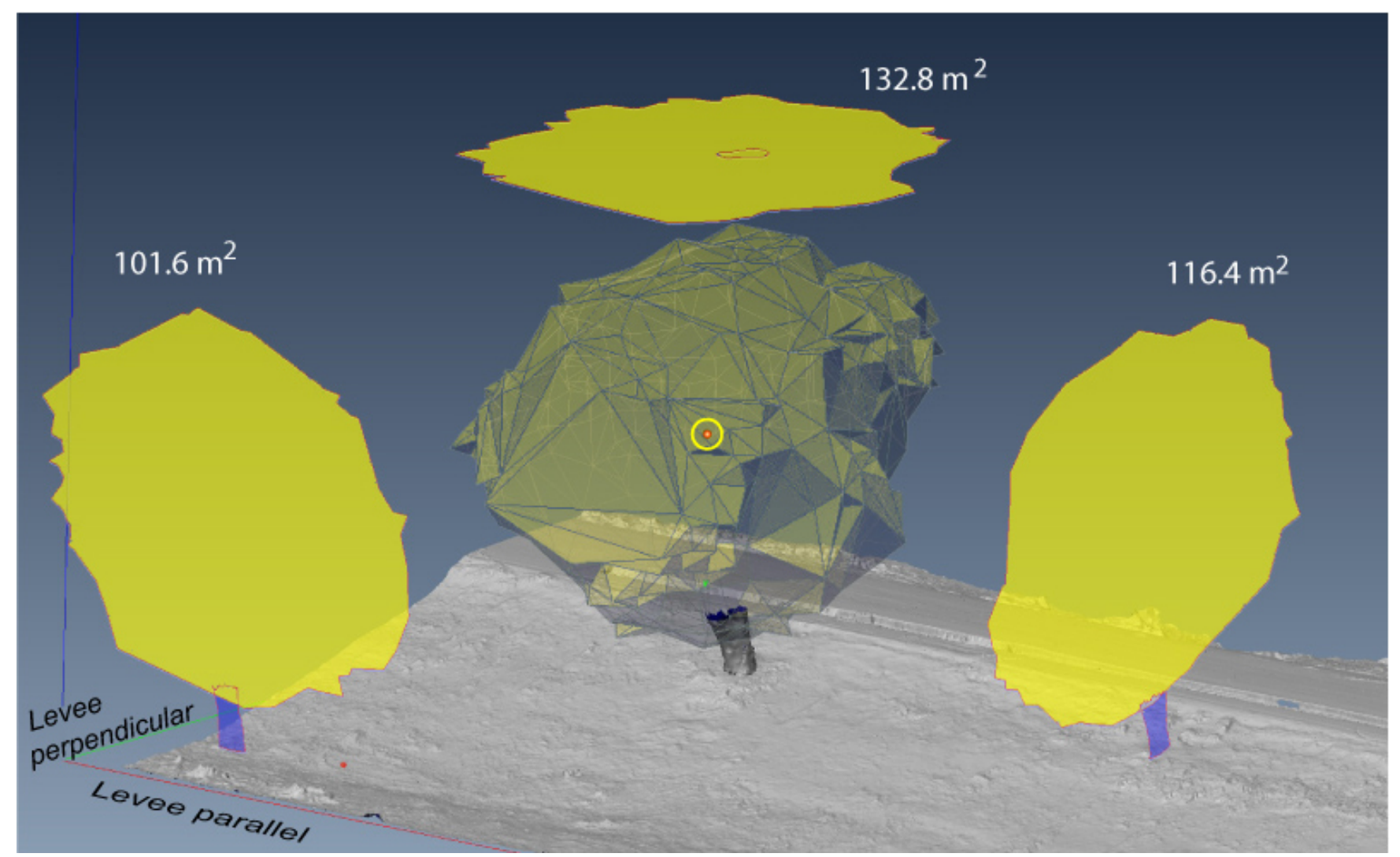

Figure 13. Levee parallel, perpendicular, and map view cross-sectional areas (solid yellow) derived from the terrestrial light detection and ranging point cloud canopy mesh (transparent yellow with blue wireframe of the mesh) of the landside tree, proximal to the seepage trench, Twitchell Island, California, 2012. The tree trunk cross-section is in transparent blue. The yellow circle at the center of the mesh is the three-dimensional centroid location and the levee is shown as a 2-centimeter bare-earth topographic model (gray). Twitchell Island, California, 2012. (m², square meter). 


\section{Conclusions}

We used terrestrial light detection and ranging (T-Lidar) data collected before, during, and after a centerline levee seepage test to assess the centimeter-scale stability of two trees located on the levee flanks, the stability of the levee crown during the seepage test, and to provide the biomorphic parameters of the landside tree for computer modeling. We collected more than 1 billion data points for this project with an average spot spacing of a few millimeters (mm; approximately, 250,000 points per $\mathrm{m}^{2}$ ) on the central section of the levee crown. Our iterative process in refining the alignment of the TLIDAR datasets and collecting much of the data with 4-point averaging resulted in a dataset with an overall alignment root mean square misfit of $2.9 \pm 0.1 \mathrm{~mm}$ for the comprehensive datasets. This allowed us to assess centimeter-scale changes in the levee surface and calculate time-varied changes in the landside and waterside tree positions. The section of this report titled, 'Key T-Lidar Methodological Approaches from This Study' outlines new approaches that advance this investigation and could be adopted by similar projects.

We observed that the waterside tree toppled (rotated 20.7 degrees) into the water during the seepage test. The landside tree rotated away from the levee crown by 5 centimeter $(\mathrm{cm})$ at a height of 2 meters $(\mathrm{m})$ on the tree, with $1 \mathrm{~cm}$ of motion during the last week of the seepage test. The paved surface of the levee crown had three regions that showed subsidence on the waterside of the trench: northern, central, and southern. The northern feature is an elongate region that subsided $2.1 \mathrm{~cm}$ over an area that has an average wide of $1.3 \mathrm{~m}$ and extends $15.8 \mathrm{~m}$ parallel from the northern end of the trench to just north of the trench's midpoint and is associated with a crack of $1 \mathrm{~cm}$ in height that formed during the seepage test on the trench wall (fig. 7). The central subsidence feature is a semicircular region on the waterside of the trench that subsided by as much as $6.25 \mathrm{~cm}$ over an area $3.4 \mathrm{~m}$ wide and $11.2 \mathrm{~m}$ long. The southern feature is an elongate region that has a maximum subsidence of $3 \mathrm{~cm}$ over an area $1.4 \mathrm{~m}$ wide and $8.2 \mathrm{~m}$ long and is associated with a number of small fractures in the pavement. We determined that there was no significant motion on the levee flank during the last week of the seepage test and that fractures associated with the tree motion were localized fractures around the trench and along the edge of the levee crown and flanks. In a separate report, the University of California Berkeley team assessed the seepage test data to relate water flow through the levee with decaying and live root systems associated with the two trees proximal to the trench. 


\section{References Cited}

FARO Technologies, Inc., 2012a, Phase shift and time of flight: Lake Mary, Florida, FARO Technologies, FARO White Paper, 5 p., http://www2.faro.com/site/resources/whitepapers.

FARO Technologies, Inc., 2012b, FARO ${ }^{\circledR}$ Scene software: Lake Mary, Florida, FARO Technologies, Inc, $h t t p: / / w w w$. faro.com.

FARO Technologies, Inc., 2013, FARO Technologies, Inc.: Lake Mary, Florida, FARO Technologies, Inc., http://www.faro.com.

InnovMetric Software Inc., 2013,PolyWorks ${ }^{\circledR}$ software suite,-Align, Inspect, IMEdit, and Modeler:

Quebec City, Canada, InnovMetric Software Inc, http://www.innovmetric.com.

Keightly, K.E., and Bawden, G.W., 2010, 3D volumetric modeling of grapevine biomass using Tripod LiDAR, Computers and Electronics in Agriculture v. 74, p. 305-312.

Kreylos, O., Bawden, G.W., and Kellogg, L.H., 2008, Immersive visualization and analysis of LiDAR data, in Bebis, G., and others, eds., Proceedings of Third International Symposium on Visual Computing 2008, Part I, Lecture Notes in Computer Science: Springer-Verlag Berlin Heidelberg, v. 5358, p. 846-855.

Lague, D., Brodu, N., and Leroux, J., 2013, Accurate 3D comparison of complex topography with terrestrial laser scanner-Application to the Rangitikei canyon (N-Z): ISPRS Journal of

Photogrammetry and Remote Sensing, v. 82 (August 2013), p. 10-26.

Pfeifer, N., and Briese, C., 2008, Laser Scanning-Principles and Applications: Vienna, Austria, Vienna University of Technology, CiteSeerX 681.7.055:621.375.826: 2008-12-30, p. 20.

Terrasolid Ltd, 2013, Terrasolid software suite-TerraScan ${ }^{\mathrm{TM}}$ point cloud classification: Helsinki, Finland, Terrasolid Ltd., http://www.terrasolid.com/.

\section{Glossary}

Alignment sphere Infrared reflective sphere targets used in ground based tripod Lidar surveying to act as reference points for the alignment of multiple Lidar scans both within a single survey and between multiple surveys collected at different times.

Azimuthal gap The largest angular distance (in degrees) between adjacent alignment targets detected by the T-Lidar scanner.

Bare earth A Lidar dataset where above ground level features, such as vegetation and signs, have been classified and removed, resulting in a "bare-earth" dataset.

Class 3R Laser A class 3R laser is considered safe if handled carefully, with restricted beam viewing. Avoid looking at the scanner at close ranges ( $0-7 \mathrm{~m}$ for most of our applications) without approved eye protection when the scanner is in operation.

Lidar Light detection and ranging is a remote sensing technology that uses laser light (pulse or continuous) to measure the distance from the instrument to a reflective target.

Mesh A triangulated surface derived from point cloud data.

Primitive A best-fit mathematical shapes (planes, cylinders, cones, and spheres) fit to point cloud data. T-Lidar Ground-based terrestrial lidar; also known as terrestrial laser scanning-TLS.

TAS Temporary alignment spheres used to improve the overall speed and quality of the alignment. 
This page left intentionally blank 